\title{
The Digitalisation of the Economy and Higher Education
}

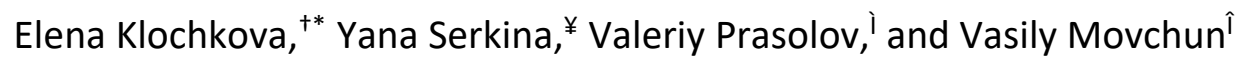

\section{Abstract}

The purpose of this article is to analyse the digital economy in higher educational institutions of the EU, the USA and the Russian Federation. The study examines topical issues and directions of higher education transformation, in the context of creating a digital learning environment. A learning process model is designed for a higher educational institution. The model will help to obtain competencies that meet the requirements of a digital economy. There is a need to adapt the education system to changes in the labour market. The activities of educational institutions and public authorities should be coordinated to prepare the optimal number of specialists that will be in demand. Corporate and university education should be integrated. Higher educational institutions should focus on increasing digital and business literacy in students, continuous digital training and retraining of teachers. The research developments are universal in nature and might be applied both as part of managing IT-learning processes of individual educational institutions and in national (regional) practices.

Keywords: Digital Economy; Higher Educational Institutions; Big Data

\footnotetext{
' Plekhanov Russian University of Economics, Russian Federation

${ }^{*}$ Corresponding Author, Email: Klotchkova.EN@rea.ru

${ }^{\sharp}$ Belgorod State National Research University, Russian Federation, Email: serkina_ya@bsu.edu.ru

' Financial University under the Government of the Russian Federation, Email: VIPrasolov@fa.ru

ÎSechenov First Moscow State Medical University (Sechenov University), Russian Federatiion, Email: druuna@bk.ru (C) 2020 Klochkova et al. This is an Open Access article distributed under the terms of the Creative Commons Attribution License (http://creativecommons.org/licenses/by/2.0), which permits unrestricted use, distribution, and reproduction in any medium, provided the original work is properly cited.
} 


\section{Introduction}

The fast development of the digital economy is becoming a key driver of global economic growth. Digital economy modernises traditional manufacturing and service industries. Digitalisation simplifies trade and procurement procedures, financial and logistics operations, and changes consumption patterns. The digitisation of economic processes creates new conditions for the functioning of global markets, as well as new approaches to analysis, forecasting and managerial decision-making. However, together with the positive effects of the digital economy, there are also new challenges and demands related to the development of the knowledge economy. Experts predict that by 2020, 1.5 million new digitised jobs will appear in the world. At the same time, $90 \%$ of the organisations currently confirm the lack of digital skills and knowledge. In this regard, it is crucial to modernise traditional education methods, which will allow improving digital skills of future specialists. In addition to their basic IT knowledge, future specialists will also gain new competencies, such as the ability of flexible thinking, the ability to make logically correct decisions and implement new ideas (Borouj \& Esfangareh, 2011).

In countries with a high share of digitalisation of the economy, such as the UK, the USA, Estonia, the role of higher education is not only in vocational training but also in creating effective models of interaction between universities and employers for training personnel. Universities in such countries continuously improve the efficiency of their financial management, as well as manage the educational process and scientific activities following the requirements of the digital economy (The ASEAN Digital Revolution, 2019). As information becomes globally available, the focus is on "teaching people how to find information, how to recognise when more information is needed, and how to evaluate the quality of the found information.
Lifelong learning, as the ability to embrace technological change", should be at the centre of education, regardless of the context for which it is intended (Digital Transformation, 2018).

Digitisation provides greater flexibility and independence in the choice of educational content, which, in turn, opens up the possibility of creating personalised learning paths (Caixa Bank Research, 2019; Ezrokh, 2019). Among the latest trends in the field of digital innovations in education, it is worth noting the rapid adaptation of online learning, for example, the emergence of blended forms of learning and online courses MOOC (massive open online courses). The positive dynamics of the development of online learning is confirmed by the growth of available online courses, the number of which is doubled every year. In 2018, in Great Britain alone, more than 4,200 courses were offered in 500 universities (Carmichael, 2019).

It is worth noting that digitalisation cannot replace direct communication between people. However, the authors note that this process can make a significant contribution to reducing the need for physical mobility through digital platforms, which allow for virtual preparatory meetings, auxiliary elements of blended learning and digital follow-up steps (Collin, 2019). A new generation is coming to higher education institutions, which exist mostly on the Internet (Ismail, 2019). A distinct transition to mobile applications is already felt: students are not tied to a place, they are detached from their workplace, place of residence (Don, 2012). The specifics of the digital generation should be taken into account. The new generation starts working after 10-12 am and till late in the evening, which is fundamentally different from older people who got used to starting work at 7 am. Therefore, previous generation representatives do not quite correctly estimate the level of $Z$ Gen $^{1}$ efficiency at work. Thus, an urgent digital transformation of education is

\footnotetext{
${ }^{1}$ The cohorts, born in between 1980 to 1995 use digital technology since a young age and are comfortable with the internet (Wood, 2013).
} 
needed, not only to adapt it to the $Z$ generation but also to use the full power of new digital technologies in the process of learning and working (Ritzer et al., 2012; Kovalev, 2018).

In summary, the research questions addressed in this study are:

- to explore the digital economy of the EU countries (Estonia), the CIS region (Russia), North American countries, and conducting a comparative analysis;

- understanding of how the use of modern information technologies, including social networks, gadgets can help to teach university students more effectively;

- evaluating the changes that have occurred in recent years and are currently taking place in the labour market, identifying new "digital" competencies that a young specialist, a university graduate, must have to be competitive in the new, changing labour market;

- building a training model based on the use of new tools of distance (online) forms of education, as well as assessing the impact of changing, "digitising" learning technologies on the economy. Such an impact is manifested in changing approaches to asset accounting, money (big data); the ongoing replacement of cash methods with the electronic payment systems, etc.

\section{Methods}

\section{Research Design}

It is necessary to determine the role of higher education in a digital society.

Higher education institutions, which are actively introducing digital technologies both in the educational process and in their activity as a whole, are beginning to occupy leading positions in the competition with higher-rated universities that use traditional types of education. By introducing new, more high-tech and flexible methods and forms of education, universities can forecast future changes in the economy (digitalisation of the global and national economies, the prevalence of electronic transactions), society and politics (electronic governments and others ). The prerequisite for such global discussions is that educational leaders can support each other, help to understand and respond to essential changes in higher education.

In the conditions of building a digital economy, higher education institutions appear as centres of competence, and the strategy and speed of informatisation of higher educational institutions are of paramount importance (Huawei Enterprise, 2019). The situation as a whole and each task separately will be considered in more detail in the following sections.

\section{Data Analysis}

Discussions at the Davos forum, within the framework of the Sustainable Development Platform until 2030, covered social, economic and environmental issues. Many scholars, politicians and business leaders agree that digitalisation can help to manage sustainable development in the region and globally (Arnold \& Fischer, 2019; Kvon et al., 2019; Shestak \& Volevodz, 2019). Thus, the interconnection of various sustainable development goals requires new knowledge and more intensive cooperation, as well as an exchange between many traditional academic disciplines.

Among the fundamental principles of reforming higher education in the framework of digitalisation of the economy and the achievement of sustainable development prospects are inclusiveness, justice, quality and lifelong learning. While the digital landscape is in a constant state of motion, it is essential to develop a visionary approach to the type of education that can help eliminate the digital divide and give the future workforce the ability to capitalise on new opportunities and challenges (Digital Marketing Institute, 2019).

Digital education specialists say that most developed and developing countries at this point in time are at the centre of the digital revolution, both in the field of education and beyond. In this regard, governments need to recognise this and 
consider it an opportunity, not something that can be feared. With this approach, the future of education is expected to bring more diverse creative opportunities for teachers and students (Dutta \& Mia, 2011; Fielder et al., 2016).
Figures 1-2 present data on the level of involvement of both residents and the business sector (including financial institutions) of the European region in the use of mobile communications. The growth rates are very significant.

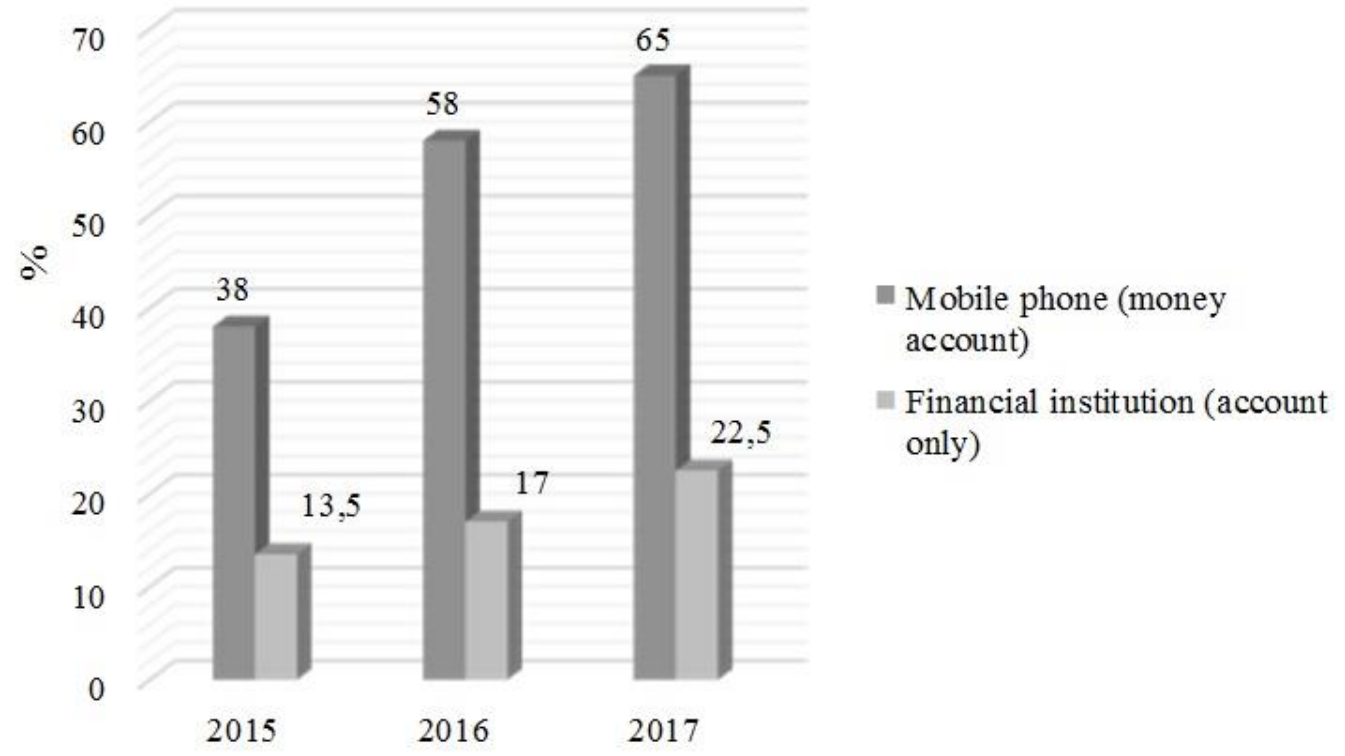

Figure 1: Increasing Financial Inclusion of Citizens and Business in EU counties, 2015-2017 (in Percentage)

Source: Elaborated by the Authors Based on OECD (EU Science Hub - European Commission, 2019).

The structure of payments itself is also changing - in the sphere of educational services (by the example of higher educational institutions), agribusiness, and the financial sector (in devices. particular, in the online transaction sector). The share of electronic transactions steadily grows, in particular, through mobile communication

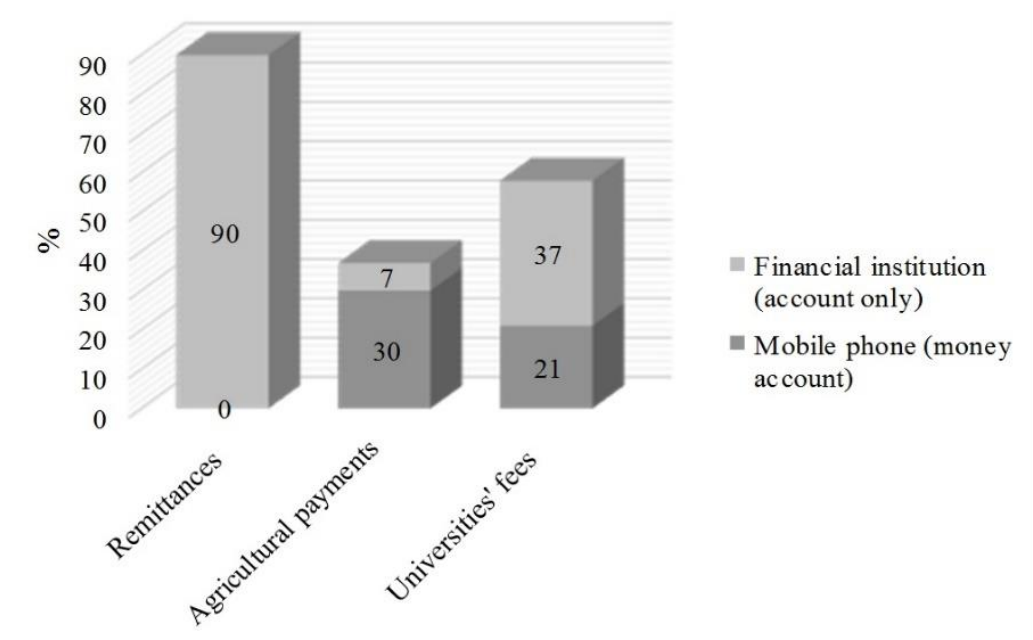

Figure 2: Advancing Towards Cashless Transactions in Everyday Life of Citizens and Business in EU Counties, 2017 (in Percentage)

Source: Elaborated by the Authors Based on OECD (EU Science Hub - European Commission, 2019). 


\section{https://doi.org/10.20896/saci.v7i4.697}

The analytical report of the DIGCOMP (Digital Competence, 2019) study provides a detailed framework for developing the digital competence of all citizens. It describes in detail all the necessary digital competencies, that is, knowledge, skills and attitudes. Hence, the key digital competencies are as follows:

- Information and data literacy: ability and skill to articulate information needs, to locate and retrieve digital data, information and content; to judge the relevance of the source and its content; to store, manage, and organise digital data, information and content.

- Communication and collaboration: ability and skill to interact, communicate and collaborate through digital technologies while being aware of cultural and generational diversity; to participate in society through public and private digital services and participatory citizenship; to manage one's digital identity and reputation.

- Digital content creation: ability and skill to create and edit digital content; to improve and integrate information and content into an existing body of knowledge while understanding how copyright and licences are to be applied; to know how to give understandable instructions for a computer system.

- Safety: ability and skill to protect devices, content, personal data and privacy in digital environments; to protect physical and psychological health, and to be aware of digital technologies for social well-being and social inclusion; to be aware of the environmental impact of digital technologies and their use.

- Problem-solving: ability and skill to identify needs and problems, and to resolve conceptual problems and problem situations in digital environments; to use digital tools to innovate processes and products; to keep up-to-date with the digital evolution" (Online Self-Assessment Tool, 2020).

Three qualification levels are defined for each competency. It is determined that digital competence is generally recognised as the key competence and is defined as confident, analytical and creative use of information and communication technologies to achieve goals related to work, education, recreation, participation in the life of society, and others (EU Science Hub - European Commission, 2019).

Figure 3 shows the dynamics of the digital economy and social development index the Global digital economy and society index. The authors decided to include in the sample more than 100 developed and developing countries to calculate this index. Namely, regions of Western Europe, North America, Eastern Europe, the CIS region, China, Japan, and Australia. Figure 3 shows an increase in this indicator for the entire analysed period - from 2015-2018 years, which testifies to the digitalisation of the world economy and the ongoing transition to a new type of society - a digital society.

Figure 4 divides this index into key components - connectivity, integration of digital technology, human capital and internet use. The latter is on the example of five EU countries, which are assigned the maximum and minimum values of this index.

As can be seen in Figure 4, in terms of Digital public services, the highest scores are in Poland, Italy, France; connectivity- Denmark; internet use- Denmark, Poland; human capitalDenmark. The aggregate values of the indices indicate that the maximum development of the digital economy and the transformation of society in 2018 is observed in Denmark, the minimum value for the European region-in Italy. 


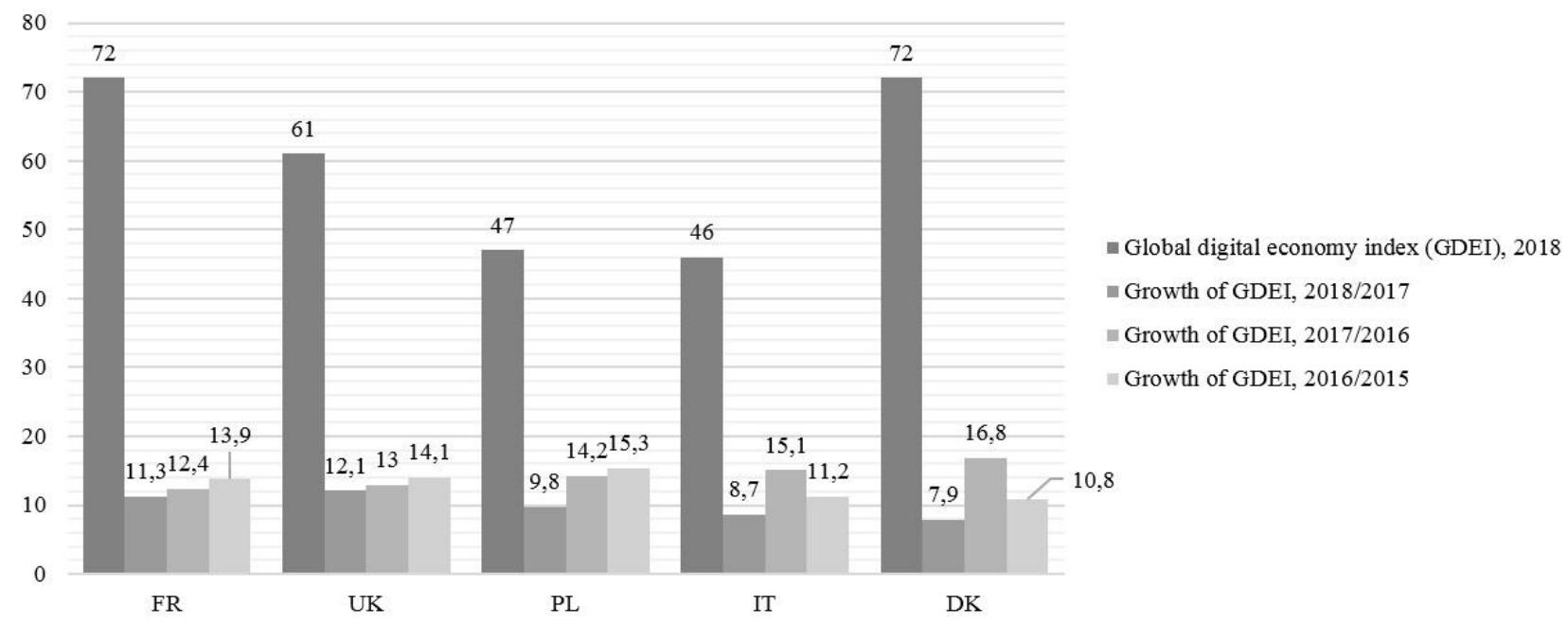

Figure 3: World Digital Economy and Society Index (DESI), 2015-2018

Source: Elaborated by the Authors Based on Dutta \& Mia (2011)\& McKinsey (2012).

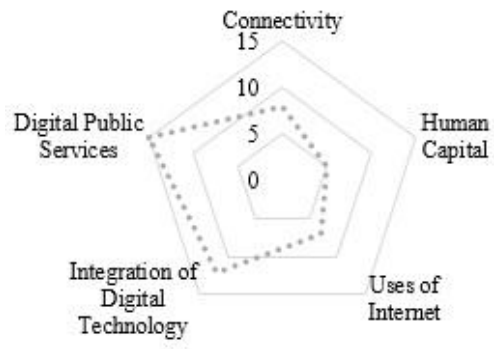

a) Poland

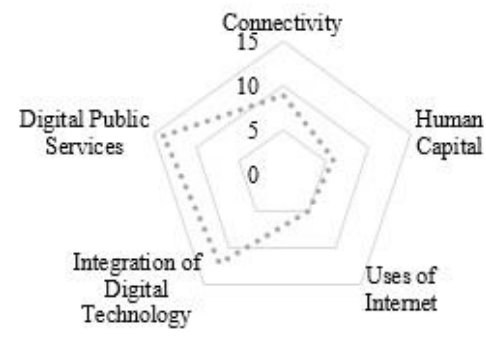

c) France

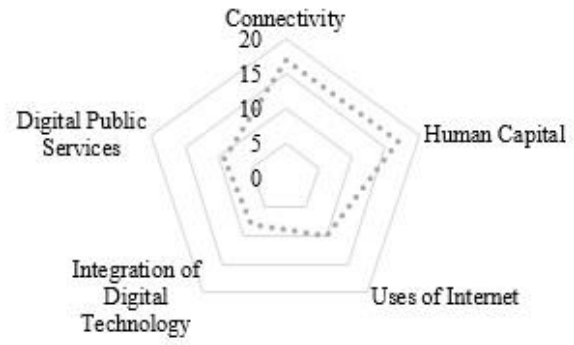

b) UK

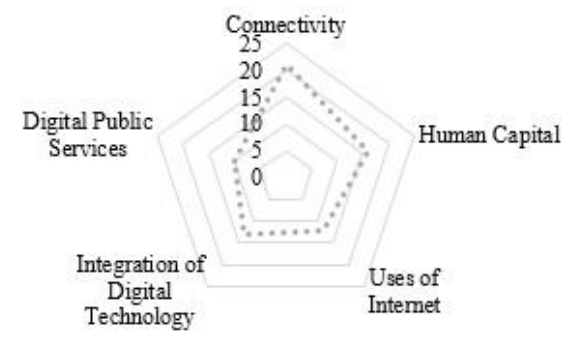

d) Denmark

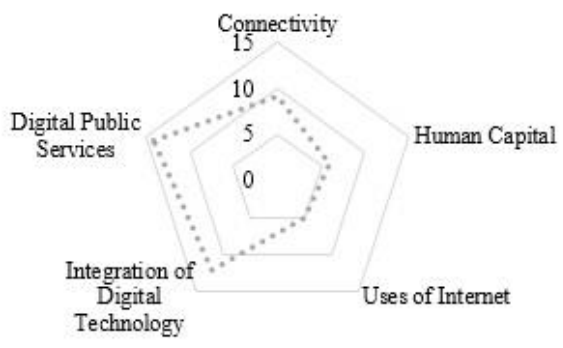

e) Italy

Figure 4: Structural components of Digital Economy and Society Index (DESI), 2018 Source: Elaborated by Authors Based on EU Science Hub - European Commission (2019) 
The following can be said concerning universities' readiness to act as critical institutions in the development of Russian digital economy.

The Global Connectivity Index $(\mathrm{GCl})^{2}$ can be used to assess the country's investment development, implementation, experience and potential in the construction of ICT infrastructure. It allows one to assess the degree of readiness of different countries for digital transformation. The index takes into account the degree of development in the country of such technologies as big data, cloud technologies, data processing centres, the Internet of things and broadband data transfer. The degree of implementation and commercialisation of these technologies is evaluated in various categories including "supply", "demand", "quality" and "potential".

\section{Results and Discussions}

Several vital advantages are presented of the use of digital teaching methods in comparison with traditional ones (see Figure 5).

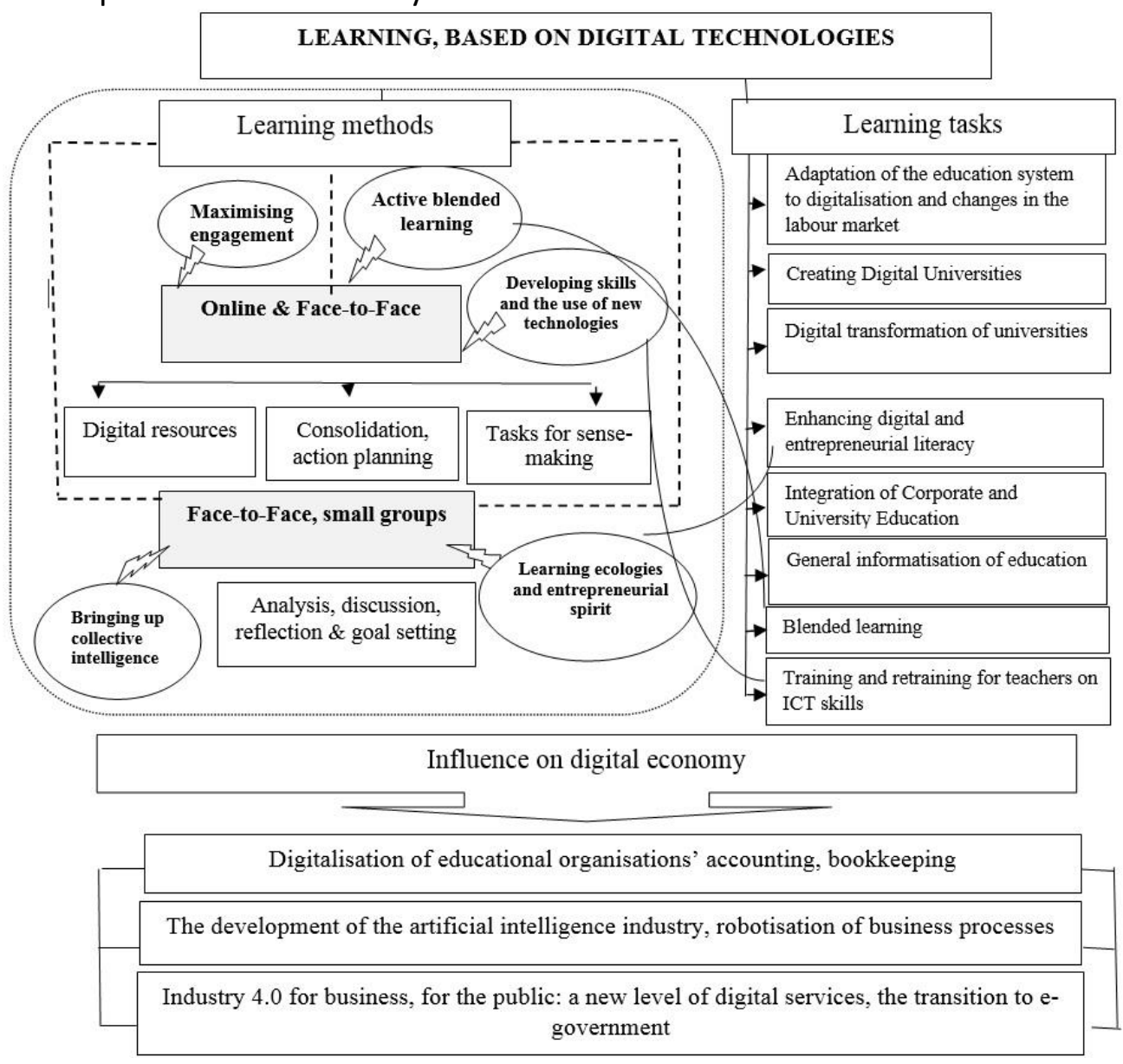

Figure 5. Structural Model of the Learning Process in Higher Educational Institutions (based on Digital Technologies and its Influence on the Digital Economy Source: Developed by the Authors

Let us consider the main structural components of this model in more detail.

\section{Maximising Engagement}

Combining face-to-face learning and online learning - active blended learning - using digital tools (gadgets, software applications, etc.). In this case, students are more interested and involved in the learning process; at the same time, skills in the use of technologies are being developed, including IT skills.

\footnotetext{
${ }^{2}$ Developed by Huawei (Huawei Enterprise, 2019)
} 
Statistics show that classrooms equipped with digital technology or a "digital" learning model are often as active as the teacher him/herself. This model provides dynamic tools with several opportunities to attract, engage and support a wide range of students, regardless of the subject.

Nowadays, there are new trends and approaches of EdTech, which include digital curricula, interactive quizzes, learning applications and personalised learning solutions. Thus, students may learn in ways that are adapted to their individual needs. Group learning based on digital technologies is also encouraged.

\section{Fostering Innovation and Creativity}

New, modern teaching technologies open up more extensive opportunities for experimentation and development of creative skills in the learning process. In general, new digital age has allowed students and teachers to study and experiment not only with new technologies and teaching tools but also with the methodology itself, going far beyond the traditional approach to school boards and textbooks. Besides, thanks to interactive platforms, applications and developments of EdTech, anyone gets the opportunity to develop, for example, public speaking skills, or engage in scientific research. These innovations inspire creativity.

For example, realising the unused creative potential of EdTech in the classroom or on campus, pioneering British agencies have invested about $f 18$ million in completely new laboratories of digital creativity at York University. In collaboration with Creative England and other key partners, York has begun using these creative digital centres to conduct meaningful research, most of which is to be conducted by students.

Using the enormous potential of digital games and interactive media for economic, social and cultural influence, York is going to demonstrate the power of digital technologies in the educational environment. As this initiative has only started, there is not much data on its progress, but it is still a piece of evidence that higher education is positively influenced by the digital society and the digital economy as a whole.

\section{Developing Skills and Use of New Technologies}

The form of training in small groups, including online, promotes the development of skills and the use of new technologies. Students and professionals need to be adaptive to keep abreast of new trends, developments and technologies. An educational institution may introduce mobile applications, online courses and online support for students. The latter might allow students to improve and develop new skills that go beyond the primary curriculum, as well as to form a new approach to lifelong learning. In general, this will allow students to improve their skills and remain competitive in the future. For an educational institution, digitalisation of education will help fill the global digital skills gap. Digital transformation will allow an institution to embrace new technologies, use them and create its own innovative products in the future (Digital Marketing Institute, 2019).

\section{Ways of Educational Digitalisation}

Now let us consider in more detail the main tasks that need to be solved in order to "digitise" the educational processes in higher educational institutions.

\section{Task 1. Adaptation of the Education System to Changes in the Labour Market under the Influence of Digitalisation.}

According to research results, over the next 1020 years, about $50 \%$ of specialities may become unclaimed. Managerial and administrative staff will be significantly reduced. Digital revolution has brought about the need to change strategies and areas of study as well as to retrain personnel. The digitalisation experience of leading countries, such as Denmark, Sweden, Finland, shows that there is a possibility when the number of new jobs (requiring a sufficiently high level of IT knowledge) for a modern digital economy may exceed the number of reduced jobs. The need for digital transformation exists in every area of science, so it is advisable to create a spectrum of master programmes like "Digital 
industry transformation" (by industry), "Digital tourism", "Digital banking", Engineers, logisticians and others with practical experience could apply for such digital learning programmes.

\section{Task 2. Training and Retraining to Study Modern Technologies.}

The teacher remains the leading figure in the educational process of the current generation, and therefore it is necessary to take effective measures for the competent growth of teaching staff in the field of digital transformation. The use of online lectures, cases and tests will bring a positive result in the process of learning new material. Teachers should prepare online lessons. It is possible to do this qualitatively if the teachers themselves are fluent in Internet technologies. In this regard, there is a need to reform the principles of work of higher educational institutions and centres of advanced training for teachers who must learn to use new IT programmes. The most critical element here is the horizontal integration of teachers in the segment of courses of the same type and the creation of online support by joint efforts, for example, based on blockchain technology. There has been a similar initiative in Russia, from representatives of the Plekhanov Russian University of Economics. They have created the website "Digital University" for teachers from different universities to interact with each other. Cloud online courses create a shared distance resource and raise teachers' competence level. Besides, it is necessary to train all teachers to use high-quality open educational resources, which have been created by universities and worldclass centres.

\section{Task 3. Blended Learning (online and face-to-} face).

It is possible to reduce the number of classroom lectures and their duration almost by half. Classroom lectures might be reduced to discussions, (e.g. discussing homework, which has been performed in the form of presentation) and to Q\&A (quality assurance) on the topic. The previous practice of combining courses into large modules has become obsolete and ineffective and should be cancelled.
Task 4. Integration of Corporate and University Education

Currently, it is a common practice when leading corporations create corporate universities to eliminate the shortcomings of modern university education. For example, there are corporate university of Sberbank of Russia or the University of Skolkovo or training centres of IT companies that have emerged as a result of the digital transformation of the economy. There are drawbacks inherent in both types of educational institutions: corporate universities provide ultramodern, but not sufficiently systematic and fundamental education, while traditional universities have not yet reached a sufficient level of modern education and new teaching technologies. Their integration is necessary, and the first step towards this may be the practice when higher education institutions start officially approving specialised courses, which have been passed by students in corporate centres.

\section{Task 5. Increasing the Level of Digital and Entrepreneurial Literacy among Students.}

While studying at school and in higher education, the new generation needs to be prepared for work in the conditions of the digital transformation of society and the market economy. They must learn to lead digital entrepreneurship, their business in the chosen field. Therefore, absolutely everyone should learn the fundamental laws of economics and entrepreneurship. Analysts believe that one of the factors of US success in economics is that an economics course is studied in all schools of the country following a single national standard, unlike other subjects, which are studied according to separate state standards. Recently, an institute of mentoring for schoolchildren has been developed in schools of Europe for new vocational guidance. Schools and higher education institutions should achieve results in teaching citizens to actively use digital skills, teaching not only the proper use of technology, but also the etiquette of networking, digital rights and cybersecurity skills, and critical assessment of network information. 
Task 6. The General Informatisation of Education.

A modern IT course should be included in the curriculum so that students can study cloud computing, the Internet of things, work with big data, blockchains. It should be noted that Barak first proposed the widespread study of such a subject in universities and schools of the United States Obama in 2016 in his address "Computer Science for All". In that address, the need for mastering computer science was emphasised. Computer science provides new basic knowledge and skills, which are necessary to create economic opportunities and social mobility; it also affects every sector of the economy.

\section{Task 7. Introducing the System of Learning at a Different Pace.}

With the digital transformation, the possibility has emerged of learning at different paces in higher education. Online courses allow students to combine work with studies and thus, they can choose their individual learning speed. A new system of adaptive education can serve as an argument in favour of this type of learning. In this system, it is allowed to change the complexity and content of courses, depending on the student's intellectual level.

\section{Task 8. The Creation and Transformation of Universities into Digital Universities.}

Universities should be digitally transformed; they should contain financial management and modern tools of educational and scientific activities. Separate activities of individual services and faculties need to be integrated into a unified system of interaction between the university and the outside world, using the range of network communication channels, such as:

- Monitoring the university's status in social networks;

- Taking the necessary measures to create a positive image of the university;

- Creating original marketing materials for target audiences, especially for foreign applicants who are unable to visit the university and form their understanding of it based on data from the Internet.

A promising direction will be the creation of first universities that combine the efforts of several universities to retrain personnel in the field of the digital economy. As a result, the digitalisation of educational processes in higher education institutions should affect, in general, the main business processes in the state economy (see Figure 5).

Concerning active blended learning ( $A B L)$, specialists of the University of Northampton note that this learning approach is focused on student activities, which include increased interaction between students and teachers, as well as between the students themselves, and the student with his/her group. However, the autonomy and freedom of action that students receive at the same time erode the specific tasks of the educational process (Don, 2012). The majority of teachers working in higher educational institutions emphasise the importance of communication in social networks between the leadership of universities, teachers and students themselves. Many believe that today almost all educational and ideological work with students should be transferred to the network (Schwarz, 2010). At the moment, many universities and their individual departments have created pages in social networks. However, communication between the lecturer and students, the dean and students of the faculty, the rector and students of the university is not enough. Indeed, the personal communication of a teacher, administration and student is one of the critical elements of university work. Social networks help instantly spread information about events taking place in a team, the best publications, grants, trips abroad, world professional achievements, and many others (Kovalev, 2018; Spencer, 2019).

In order to be competitive in the labour market in the upcoming era of a fully digital economy, one must be able to:

- identify, download, store, organise and analyse digital information, depending on relevance and purpose; 
- share data and resources in the digital environment, interact effectively in online communities, have intercultural awareness;

- create and edit new, regularly updated content; have skills of integration and processing of previous experience and knowledge; prepare media materials and programmes;

- possess knowledge in the field of intellectual property, be able to identify and prevent the occurrence of IT risks;

- use the most appropriate digital tools following the purpose or need;

- solve conceptual problems using digital tools (Don, 2012).

Many government representatives and industry leaders agree that at the moment one of the most important tasks is the creation of a roadmap for digital economy's development, along with ICT improvement and analytical tools (which become a significant development factor) (Huawei Enterprise, 2019). Digital transformation plays a unique role in the strategic renewal of modern higher educational institutions. The latter is not only about reequipment of IT-resources, but also about a kind of reloading of human potential, professional capital upgrade, corporate culture modernisation, as well as educational institution's socialisation, communication and optimisation of all its internal processes. For each university, it should be imperative to carry out training and retraining of specialists (including managers of organisations and enterprises) in the field of digitalisation (Dutta \& Mia, 2011; Don, 2012).

\section{Conclusion}

Higher education can be improved with the use of digital developments, new platforms, designs and methodologies, along with a creative, strategic approach and a passion for teaching. As a result, universities, colleges, and other educational institutions will educate future creative, innovative, and forward-looking people who will strive to achieve big goals for society as a whole.
Universities should be drivers of the digital transformation of the economy and society. Digital students and graduates, who have been using the Internet and social networks from childhood, are able to come up with new digital ideas even before graduation. In this regard, it becomes essential that the structure of universities, their technology parks and business incubators, together with teachers, contribute to the emergence and establishment of university youth start-ups. Business incubators should provide the working area, initial capital and accounting services. Hence, it is necessary to create venture funds at universities (at the expense of tuition payments). Issues of joint ownership of start-ups between university's technology parks, private founders, students and teachers should be resolved at the legislative level. It should also be determined for how long the company is going to stay in the incubator.

Undoubtedly, a modern university must adapt to the conditions of unprecedented modernisation in order to preserve its unique qualities and competitive advantages. It is also crucial for the university to build its development strategy and areas for research and development. Higher education institutions should attract foreign experts and students, open international campuses, strengthen academic mobility programmes for scholars and students in order to integrate into the international educational environment.

\section{References}

Arnold, M., \& Fischer, A. (2019). Digitization and Sustainability: Threats, Opportunities, and Trade-Offs. In Responsible, Sustainable, and Globally Aware Management in the Fourth Industrial Revolution (pp. 1-28). IGI Global. doi:10.4018/978-1-5225-7638-9.ch001

Borouj, S., \& Esfangareh, N. (2011). Digital economy and tourism impacts, influences and challenges. Procedia - Social and Behavioral Sciences, 19, 308-316.

doi:10.1016/j.sbspro.2011.05.136

Brečko, B., Ferrari, A., Vuorikari R., \& Punie Y. (2016). The Digital Competence Framework for 
Consumers. Joint Research Centre Science for Policy Report; EUR 28133 EN.

Caixa Bank Research (2019). The digital era and its role in the economy. Retrieved on 01 January 2020 from, http://www.caixabankresearch.com/en/la-eradigital-y-su-papel-en-la-economia-d2

Carmichael, S. (2019). The Flash Report: The Global Digital Economy. Harvard Business Review. Retrieved on 01 January 2020 from, https://hbr.org/2016/04/the-flash-report-theglobal-digital-economy

Collin, N. (2019). The Digital Economy.

Cairn.info. Retrieved on 01 January 2020 from, https://www.cairn-int.info/article-

E_NCAE_026_0001--the-digital-economy.htm

Digital Competence (2019). EU Science Hub.

Retrieved on 01 January 2020 from, https://ec.europa.eu/jrc/en/digcomp

Digital Marketing Institute (2019). What's the Role of Higher Education in a Digital Society? Retrieved on 01 January 2020 from, https://digitalmarketinginstitute.com/blog/wha ts-the-role-of-higher-education-in-a-digitalsociety

Digital Transformation: Higher Education and Research for Sustainable Development (2018). German Academic Exchange Service, Bonn. Retrieved on 01 January 2020 from, https://www2.daad.de/medien/veranstaltunge n/workshop/experts_on_digitalisation_in_highe r_education_and_research_for_sustainability_ dec2018.pdf

Don, T. (2012). Macrowikinomics: Reboting business and the world. Retrieved on 01 January 2020 from, http://elib.bsu.by/bitstream/123456789/20612 8/1/62-136-1-SM.pdf.

Dutta, S., \& Mia I. (2011). The Global Information Technology Report 2010-2011. World Economic Forum, 24, 331-391.

EU Science Hub - European Commission (2019). DIGCOMP: A Framework for Developing and Understanding Digital Competence in Europe. EU Science Hub - European Commission. Retrieved on 01 January 2020 from, https://ec.europa.eu/jrc/en/publication/eurscientific-and-technical-researchreports/digcomp-framework-developing-andunderstanding-digital-competence-europe

Ezrokh, Y. (2019). HR Perspectives of Russian Universities: Who Will Teach in the Near Future? The Education and science Journal, 21(7), 9-40. doi:10.17853/1994-5639-2019-7-940

Fielder A., Vuorikari, R., Rodríguez-Priego N., \& Punie, Y. (2016). Background Review for Developing the Digital Competence Framework for Consumers. JRC Technical ReportsEUR 28196 EN.

Huawei Enterprise (2019). The role of universities in the digital economy: Huawei presented its vision for the development of the educational industry. Retrieved on 01 January 2020 from, https://e.huawei.com/kz/news/ru/2017/20171 1021525

Ismail, N. (2019). Multi-cloud and application services are fuelling digital transformation. Information Age. Retrieved on 01 January 2020 from, https://www.information-

age.com/fuelling-digital-transformation123470425/

Kovalev, M. (2018). Education for the digital economy. Digital Transformation, 1, 37-42.

Kvon, G., Prokopyev, A., Shestak, V., Larionova, A., \& Shikh, E. (2019). Features of Cost Advantages from Implementation of EnergySaving Projects. International Journal of Energy Economics and Policy, 9(3), 53-58.

doi:10.32479/ijeep.7645

McKinsey (2012) Global Institute, Urban World: Cities and the rise of the consuming class.

Retrieved on 01 January 2020 from, https://www.mckinsey.com/featuredinsights/urbanization/urban-world-cities-andthe-rise-of-the-consuming-class

Online Self-Assessment Tool (2020). Digital Skills Accelerator. Retrieved on 01 January 2020 from,

https://www.digitalskillsaccelerator.eu/learning -portal/online-self-assessment-tool/ 
Ritzer, G., Dean, P., \& Jurgenson, N. (2012). The Coming of Age of the Prosumer. American Behavioral Scientist, 56(4), 379-398. doi:10.1177/0002764211429368

Schwarz, M. (2010). Social Innovation. Innovation. Retrieved on 01 January 2020 from, http://www.citeulike.org/group/7644/article/5 204389

Shestak, V., \& Volevodz, A. (2019). Modern requirements of the legal support of artificial intelligence: a view from Russia. Russian Journal of Criminology, 13(2), 197-206.
Spencer, J. (2019). The Risks and Benefits of Digital Currency. Entrepreneur. Retrieved on 01 January 2020 from, https://www.entrepreneur.com/article/302778 The ASEAN Digital Revolution (2019). Retrieved on 01 January 2020 from,

https://www.atkearney.com/digitaltransformation/article?/a/the-asean-digitalrevoluti-1

Wood, S. (2013). Generation Z as consumers: trends and innovation. Institute for Emerging Issues: NC State University. Retrieved on 01 January 2020 from, https://iei.ncsu.edu/wpcontent/uploads/2013/01/GenZConsumers.pdf 